\title{
Large-scale vegetation responses to terrestrial moisture storage changes
}

\author{
Robert L. Andrew ${ }^{1}$, Huade Guan ${ }^{1,2}$, and Okke Batelaan ${ }^{1,2}$ \\ ${ }^{1}$ School of the Environment, Flinders University, Bedford Park, 5042, Australia \\ ${ }^{2}$ National Centre for Groundwater Research and Training, Bedford Park, 5042, Australia \\ Correspondence to: Robert L. Andrew (robert.andrew@flinders.edu.au)
}

Received: 16 October 2016 - Discussion started: 1 November 2016

Revised: 26 March 2017 - Accepted: 13 July 2017 - Published: 8 September 2017

\begin{abstract}
The normalised difference vegetation index (NDVI) is a useful tool for studying vegetation activity and ecosystem performance at a large spatial scale. In this study we use the Gravity Recovery and Climate Experiment (GRACE) total water storage (TWS) estimates to examine temporal variability of the NDVI across Australia. We aim to demonstrate a new method that reveals the moisture dependence of vegetation cover at different temporal resolutions. Time series of monthly GRACE TWS anomalies are decomposed into different temporal frequencies using a discrete wavelet transform and analysed against time series of the NDVI anomalies in a stepwise regression. The results show that combinations of different frequencies of decomposed GRACE TWS data explain NDVI temporal variations better than raw GRACE TWS alone. Generally, the NDVI appears to be more sensitive to interannual changes in water storage than shorter changes, though grassland-dominated areas are sensitive to higher-frequencies of water-storage changes. Different types of vegetation, defined by areas of land use type, show distinct differences in how they respond to the changes in water storage, which is generally consistent with our physical understanding. This unique method provides useful insight into how the NDVI is affected by changes in water storage at different temporal scales across land use types.
\end{abstract}

\section{Introduction}

In many parts of the world, such as Australia, water storage is the dominant limiting factor in vegetation growth (Donohue et al., 2008; Nemani et al., 2003). As such, changes in water storage can lead to changes in vegetation mass and greenness (Yang et al., 2014). As vegetation plays a vital role in gross primary production and the carbon and hydrological cycles, studies of the temporal and spatial variation of vegetation are vital for understanding ecosystem performance and its climatic responses (Campos et al., 2013). As the climate and water resources change as a result of natural and anthropogenic influences, understanding how fluctuations in water storage are associated with biomass changes can have a profound importance for the future.

Previous studies have used different hydrological parameters to examine the effect of hydrological changes on ecosystem performance. Most commonly, precipitation and soil moisture have been used as defining variables (Chen et al., 2014; Huxman, 2004; Méndez-Barroso et al., 2009; Wang et al., 2007). Both of these have shown generally meaningful correlations with ecosystem performance (by various measures such as the normalised difference vegetation index, NDVI, and above-ground net primary production). However, both indicators have shown limitations. The total amount of precipitation is not necessarily used by vegetation in an ecosystem. Part of precipitation is lost from the ecosystem as runoff or soil evaporation (Liping et al., 1994). Only the part which is retained as soil moisture in the root zone can be viably consumed by vegetation and this is categorised as "effective precipitation" (Bos et al., 2009). For a given amount of rainfall, the fraction of effective precipitation varies spatially due to differing geographical features, soil types, and vegetation cover conditions. Soil moisture gives a better representation of the water that is available to plants. However, in situ soil moisture data are generally limited and spatially 
(vertically and horizontally) sparse. Estimations from land surface models are often highly uncertain (Chen et al., 2013).

Recently Yang et al. (2014) used monthly total waterstorage anomalies (TWS*) from the Gravity Recovery and Climate Experiment (GRACE) to examine hydrological controls on variability in surface vegetation. GRACE provides monthly global terrestrial water storage derived from variations in the earth's gravity field. The authors suggested that where large surface water reservoirs do not exist, GRACE TWS changes are mostly from soil moisture and groundwater, making it ideal for examining hydrological controls on vegetation activity. GRACE is found to be a good indicator of seasonal variability in surface greenness over mainland Australia (Yang et al., 2014). For the period 2003-2010, for which GRACE data are available, changes in the NDVI* are explained more strongly by GRACE TWS* than by precipitation, suggesting it poses a more direct influence on surface greenness and ecosystem performance.

GRACE TWS gives the total relative water storage at a resolution of a few hundred kilometres. It is the sum of surface water, soil water, groundwater, ice etc. We previously developed an approach to "split" GRACE TWS into shallow and deep subsurface storage components using a discrete wavelet decomposition (Andrew et al., 2017). In this study, we aim to expand on the general findings of Yang et al. (2014) by decomposing GRACE TWS* into different temporal components and analysing them against the NDVI* . Given that root zone water storage is the source of water to vegetation we hypothesise that decomposed TWS* data that reflect the temporal pattern of soil moisture in the root zone will perform better than the total TWS* in association with the NDVI*.

The questions we seek to address are (1) does the decomposed TWS* data show a better relationship to the NDVI* than the raw TWS* data, (2) how does the sensitivity of the NDVI $^{*}$ in response to changes in TWS* vary spatially, and (3) which temporal components of TWS* are most significant in influencing the NDVI* for different land use types across Australia?

\section{Data}

\subsection{GRACE data}

We use gridded GRACE total water storage (TWS) data from the University of Texas Center for Space Research (CSR) and NASA's Jet Propulsion Laboratory (JPL). The gridded GRACE data sets are freely downloadable from the GRACE Tellus website (http://grace.jpl.nasa.gov/data/ get-data/). Data are suitably post-processed, including application of the recommended scaling correction (gain factors) (Swenson and Wahr, 2006). The scaling coefficients are in part designed to remove leakage errors (Landerer and Swenson, 2012). Monthly data from March 2003 to December 2014 are used. The average of the two data sets is calcu- lated for each cell at each month to reduce the uncertainty. The data are presented spatially in 100 by $100 \mathrm{~km}$ grid cells. Although this is not the true resolution of GRACE, with the appropriate gain factors applied the 100 by $100 \mathrm{~km}$ gridded data are suitably recovered (Landerer and Swenson, 2012). An alternative would be to aggregate the other data set in this study (NDVI) to a larger scale to match true GRACE resolution, but this would increase errors in land and vegetation cover. We selected which cells should be included based on a shape file of Australia. If at least two thirds of the cell is part of the continent then it is included; this eliminates some cells which covered only a small coastal land mass.

There are a few occurrences of missing data in the GRACE data set. These months of missing data are filled with a simple temporal interpolation using the months either side. Because of the monthly temporal resolution this is deemed appropriate and maintains the average seasonal cycle well (Long et al., 2015).

\subsection{NDVI data}

We use GIMMS 3g NDVI data for the same time period as the GRACE data. The data are downloaded from the NASA database. The NDVI data are produced at a higher spatial resolution $\left(0.25\right.$ by $\left.0.25^{\circ}\right)$ than GRACE. This data are rescaled to match the GRACE cell size using the resampling tool in ArcGIS. Like the GRACE data, only cells which contain at least two thirds land are used and missing data are filled by a temporal interpolation.

\subsection{Land use type data}

The Moderate-resolution Imaging Spectroradiometer (MODIS) land use data are used to identify different land use types across Australia (product MCD12Q1). They are freely available online from http://glcf.umd.edu/data/lc/. With regards to rescaling and cell selection, the same procedures are applied as in the case of NDVI data. In Australia, MODIS land use type data define 12 different classes of land use. This is reduced to five (or six including barren land) classes by grouping similar classes such as different types of forests. The resulting land use types are forest, shrubland, savanna, grassland, and agricultural land (Table 1).

Figure 1 shows the spatial distribution of different land use types across Australia, grouped as previously stated (Table 1). Note that no analysis is performed for areas considered barren due to a lack of vegetation.

\section{Methodology}

\subsection{Calculating anomalies}

For variables with strong seasonality, a statistical relationship between them does not necessarily mean that a physical relationship exists. Climatological anomalies of both GRACE 

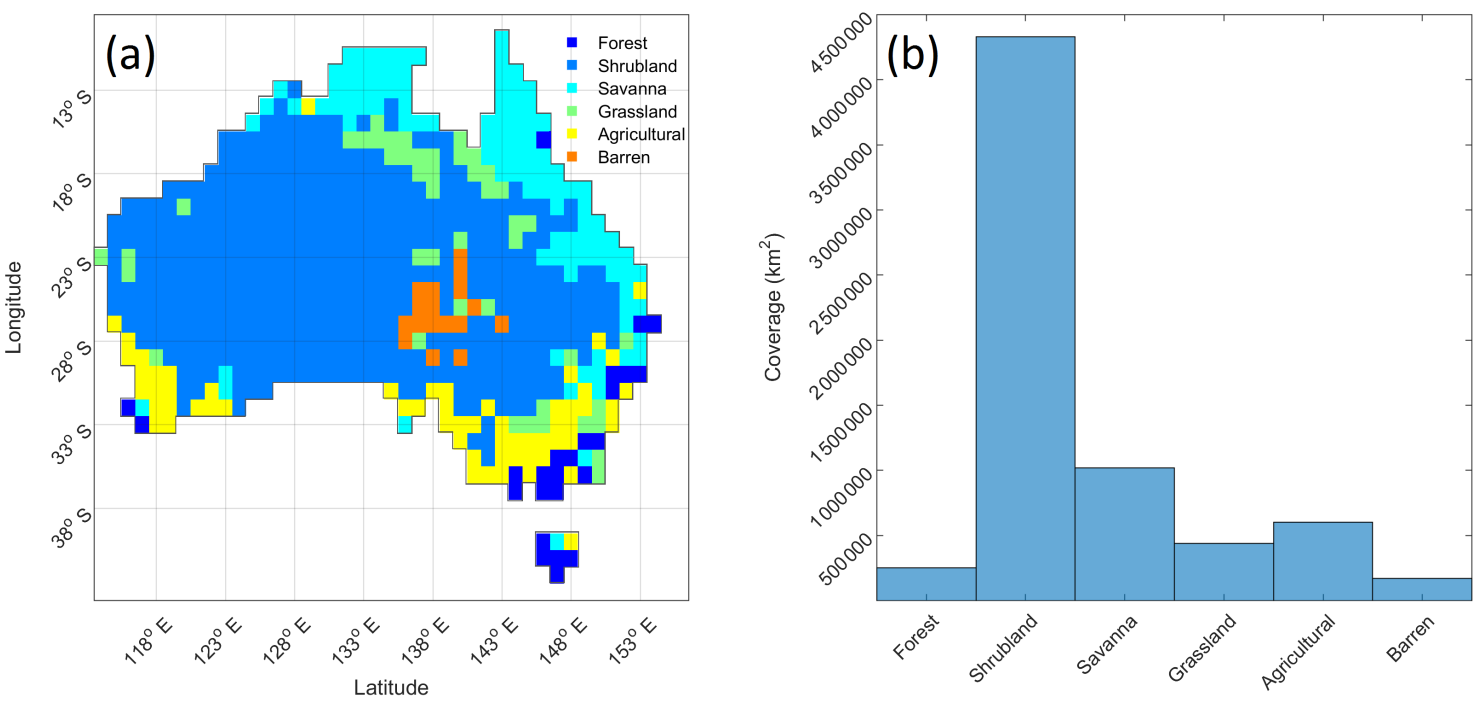

Figure 1. (a) The spatial distribution of various land use types across Australia and (b) the area covered by each land use type.

Table 1. Subcategories of land use types as defined by MODIS.

\begin{tabular}{ll}
\hline MODIS land use type & $\begin{array}{l}\text { Classification in } \\
\text { this study }\end{array}$ \\
\hline $\begin{array}{l}\text { Evergreen needleleaf forest } \\
\text { Evergreen broadleaf forest } \\
\begin{array}{l}\text { Deciduous needleleaf forest } \\
\text { Deciduous broadleaf forest }\end{array}\end{array}$ & Forest \\
\hline $\begin{array}{l}\text { Closed shrublands } \\
\text { Open shrublands }\end{array}$ & Shrubland \\
\hline $\begin{array}{l}\text { Woody savannas } \\
\text { Savannas }\end{array}$ & Savanna \\
\hline Grassland & Grassland \\
\hline $\begin{array}{l}\text { Cropland } \\
\text { Cropland/natural vegetation mosaic }\end{array}$ & Agricultural land \\
\hline Barren & Barren \\
\hline
\end{tabular}

TWS and the NDVI are used in order to remove seasonality in the data which would otherwise result in large but irrelevant and misleading correlations between variables examined in this study.

The anomalies are calculated following the method of Yang et al. (2014),

$X^{*}(i j)=X(i j) \frac{1}{n} \sum_{j=1}^{n} X(i, j)$,

where $X^{*}$ represents the climatological anomaly of $X$ (i.e. raw GRACE TWS), $i$ is the month, $j$ is the year, and $n$ is the total number of years.

New lagged GRACE TWS* anomaly data sets are produced by offsetting the GRACE data from the NDVI data by 1 to 6 months. This is to allow any delays in the NDVI response to water storage to be revealed (Farrar et al., 1994).

\subsection{Wavelet decomposition}

GRACE TWS* is decomposed into different signals using a discrete wavelet transform. Introduced in the early 1980s, a wavelet is a mathematical function used to divide data series into different frequency components (Goupillaud et al., 1984). The method expresses decompositions as a multitude of smaller "waves" at different frequencies (He and Guan, 2013). The Meyer wavelet is applied here to decompose GRACE TWS* into components at different temporal scales and is suitable for this temporal data (He and Guan, 2013). This is relatively easy to achieve by means of a simple MATLAB code using the "wavdec" function. Data are decomposed into "approximation" and "detail" components, each representing a different temporal scale. Approximation series maintain trends in the data while detail series neglect trends (Nalley et al., 2012). The resulting time series are labelled $A 1, A 2, A 3, A 4$ and $D 1, D 2, D 3, D 4$ for approximations and details respectively, with the timescale increasing with the decomposition number, e.g. A1/D1 (2-month scale), $A 2 / D 2$ (4-month scale), $A 3 / D 3$ (8-month scale), and $A 4 / D 4$ (16-month scale) (Fig. 2). Essentially, from one time series eight new time series are made and four different temporal resolutions are produced. Four levels can be reasonably extracted given the data length and monthly frequency of the data. Further decomposition would result in roughly 3- and 6-year timescales, which are too coarse for a time series of only 11 years of raw data. Because all but the lowest approximation levels contribute partly to details we only use the lowest frequency approximation, along with all of the details. The sum of these $(D 1, D 2, D 3, D 4$, and $A 4)$ equals 
the raw signal (Fig. 3). So, 5 wavelet decomposition series are used for GRACE data as well as 6 lagged series for each decomposition level, giving a total of 35 water-storage time series.

\subsection{Stepwise regression}

To evaluate which of the new decomposed time series correspond to different vegetation types, we used a stepwise regression for every cell. $\mathrm{NDVI}^{*}$ is the dependent variable and the GRACE TWS* decompositions are taken as predictor variables. Given the time series of the data, 35 predictor variables are too many for a stepwise regression to function properly. The stepwise regression is run multiple times and the best predictor variables are chosen narrowing them down to nine. The choice is made based on the number of cells selected for each variable from the stepwise regression and how relevant they are given their spatial coherence. In general, the predictor variables excluded from the stepwise regression are not included in any cells across the country. The remaining variables are (subscript denotes lag in months) $D 1_{0}, D 2_{1}, D 3_{0}, D 3_{1}, D 3_{2}, D 4_{0}, D 4_{1}$, $A 4_{0}$, and $A 4_{6}$. High-frequency signals ( $D 1, D 2, A 1$, and $A 2$ ) correspond to water-storage changes of shallow soil moisture while low-frequency signals such as $D 3, D 4, A 3$, and $A 4$ correspond to deeper soil moisture or even groundwater changes. Therefore, forests should correspond with lowfrequency changes; their roots are accessing water storage that is changing at a low-frequency. Land covers dominated with grasses (shallow roots) should correspond to higherfrequency signals where moisture change is more dynamic.

\section{Results}

As a proof of concept, the relationships between raw GRACE TWS* versus NDVI* and decomposed GRACE TWS* versus NDVI* are compared (Fig. 4). The results for the decomposed TWS ${ }^{*}$ data are based on a selection of decomposed time series selected by the stepwise regression. A time series example of the results from an individual cell is demonstrated in Fig. 5. For each cell the correlation coefficient between NDVI* $^{*}$ and the regression estimates $(r)$ is calculated. In order for the tests to be comparable, lagged data are not included in the decomposed TWS data set for this demonstration, it shows purely how decomposed data improve the relationship. A scatter plot of the $r$ values shows a clear improvement in the relationship when decomposed GRACE TWS* data are used as opposed to raw data, with all points above the $1: 1$ line. The Student's $t$ tests confirmed that the stepwise regression results are statistically highly significant with a $p$ value of 0.00014 .

Lagged data ensure that the relationship between NDVI* and TWS $^{*}$ is well represented but the decomposed frequency of the TWS* data is the focus of this study. Al- though the stepwise regression is performed using nine variables including lags where suitable, the results herein are presented as only five variables, $D 1, D 2, D 3_{\mathrm{L}}, D 4_{\mathrm{L}}$, and $A 4_{\mathrm{L}}$. For each detail or approximation level using different lags, one variable is created by combining the results of different lagged data sets together to present the results, i.e. $D 3_{\mathrm{L}}=D 3_{0}+D 3_{1}+D 3_{2}$.

It is important to recognise how the variables that are included in the stepwise regression vary spatially, to understand how vegetation responds to different temporal patterns of water storage across the continent. For a variable to be included in the stepwise regression it does not have to show a positive correlation. Figure 4 shows which variables are included in the regression for each cell across Australia. Where lagged data are not used (D1 and D2) the colour denotes whether the coefficient is positive or negative. Where lagged data are used $\left(D 3_{\mathrm{L}}, D 4_{\mathrm{L}}\right.$, and $\left.A 4_{\mathrm{L}}\right)$ the colour denotes whether all coefficients for a cell have the same sign or not. Figure 4 shows that while $A 4_{\mathrm{L}}$ is included across most of the country, one of the lagged data sets, $A 4_{6}$, has a large number of negative coefficients included in the regression (see Fig. A1). A possible explanation for this is that NDVI is susceptible to the "memory effect", where past inputs and outputs affect responses in the system (Shook and Pomeroy, 2011).

Overall, the number of cells covered by each different decomposition level increases as the decomposition timescale increases. This shows that, in general, the NDVI changes pertain to longer timescale water-storage changes and are not as much affected by changes on a monthly timescale.

While understanding which variables are used in each cell is important, it is more important to know their relative impact on NDVI*. The relative weight of each variable is calculated to show the importance of each on vegetation in different land use types. Of the included variables in each cell, the relative weight of each variable is calculated as

$W=\frac{\left(C \cdot \sigma_{X}\right)}{\sigma_{\mathrm{NDVI}}}$,

where $W$ is the relative weight, $\sigma_{X}$ is the standard deviation of the decomposed data anomaly $(X), C$ is the coefficient of $X$ in the regression, and $\sigma_{\text {NDVI }}$ is the standard deviation of the NDVI anomaly. Figure 7 shows which variable has the highest relative weight in each cell. $A 4_{\mathrm{L}}$ is the dominant variable, covering the majority of the country, and is a lowfrequency trended signal. D2, a higher-frequency signal, is the second most dominant variable and shows generally clear spatial coherence.

The relative weights for all cells of each land use type are combined and presented as a relative weight percentage per land use type (Fig. 8). Forested areas have only low-frequency decompositions included, with $A 4_{\mathrm{L}}$ being the most dominant. This is expected as forests have deep root systems, which tap into water stores that change slower than shallower soil moisture (Backer et al., 2003). Therefore, their 


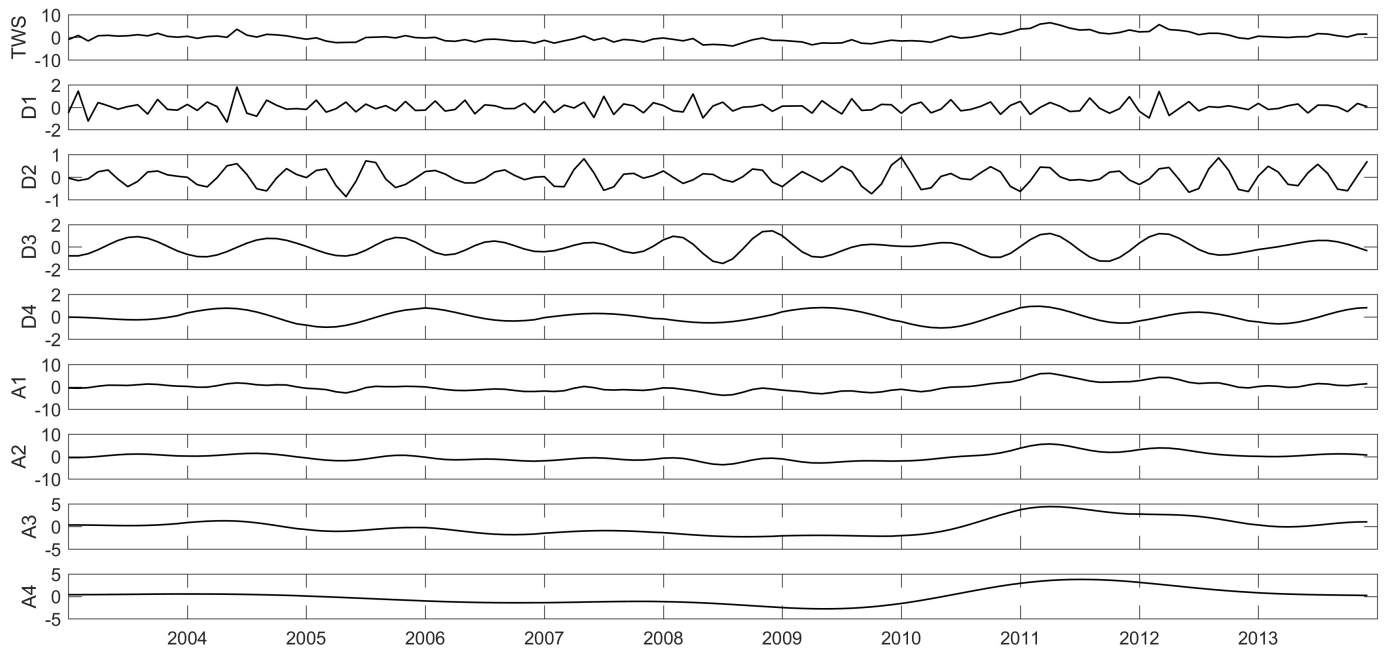

Figure 2. An example of a wavelet decomposition from a cell in central South Australia $\left(29^{\circ} \mathrm{S}, 136^{\circ} \mathrm{E}\right)$. Note the visible trends in the approximations $(A 1-A 4)$, which are normalised in the details $(D 1-D 4)$.

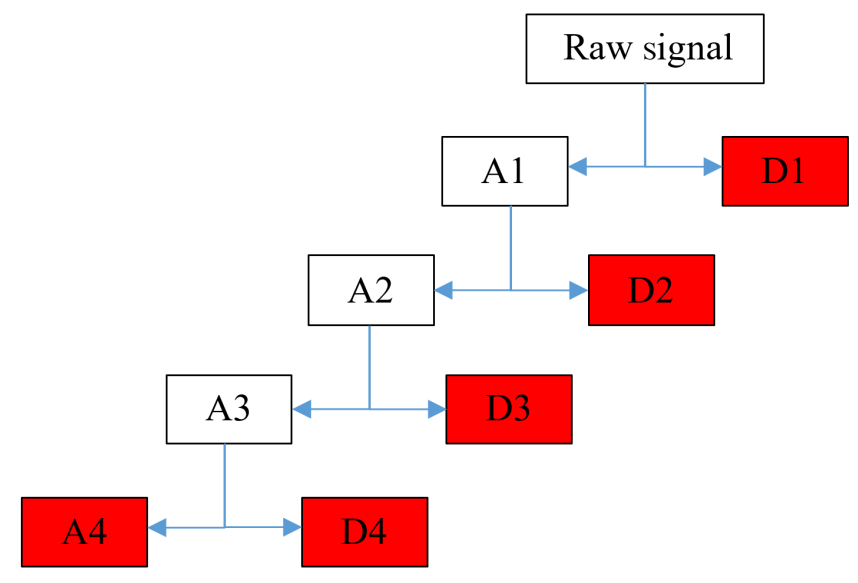

Figure 3. The structure of a wavelet decomposition; decomposition levels used in this study are highlighted in red.

water store is less likely to be affected by short-term rainfall or evaporation, relying more on long-term hydrological trends and variabilities. Shrubland, savanna, and grassland show nearly identical distributions of weights. Grassland shows a marginally higher percentage of the $D 1$ and $D 2$ variables, which is consistent with our physical understanding as they are fed by shallow soil moisture which varies at high temporal frequencies. While all are defined differently, the three land use types have overlapping characteristics, most commonly the widespread presence of short grasses (Friedl et al., 2002) and shallow root systems. These short grasses respond to changes in the shallow top layer of the soil, which is influenced at high temporal frequencies by rainfall events and evaporation. The similarity in the results of these three land use types suggests that they are hardly distinguishable by GRACE, likely due to the spatial extend of GRACE cells.
For example, where sparse trees exist in a savanna, their lack of response to the shallow soil moisture may be negligible compared to the large coverage of grasses, thus showing a very similar pattern to grassland.

\section{Discussion}

Using wavelet decomposed GRACE TWS* data proved to improve the correlation between water storage and NDVI*. A previous study by Yang et al. (2014) showed that GRACE is a superior indicator of surface greenness than soil moisture or precipitation, which were earlier used as indicators (Chen et al., 2014; Huxman, 2004). Temporal decomposition of GRACE TWS* produces a new temporal dimension that allow the data to be analysed to their full potential. As demonstrated in Fig. 4, the decomposed TWS* data are more closely associated with the surface greenness than the raw TWS* data. Furthermore, a better understanding of how surface greenness changes with water storage spatially and temporally is achieved, with different levels of decomposition existing in spatial clusters across the country. The dominance of $A 4_{\mathrm{L}}$ as the most highly weighted predictor variable indicates that generally vegetation responds to low-frequency (interannual) changes in water storage across Australia.

An interesting result is the large number of negative coefficients produced from the stepwise regression for $A 4_{6}$. Two possible explanations exist. A 6-month lag may correspond to the opposite seasons (e.g. wet 6 months ago, dry now), potentially serving as an indicator of water-storage potential. Alternatively, vegetative systems may be susceptible to the memory effect. Specifically, this would suggest that for most of the continent, trends at the $A 4$ scale (roughly annual) influence vegetation responses to water-storage changes 6 months later in these areas. Such a memory effect can serve as an in- 

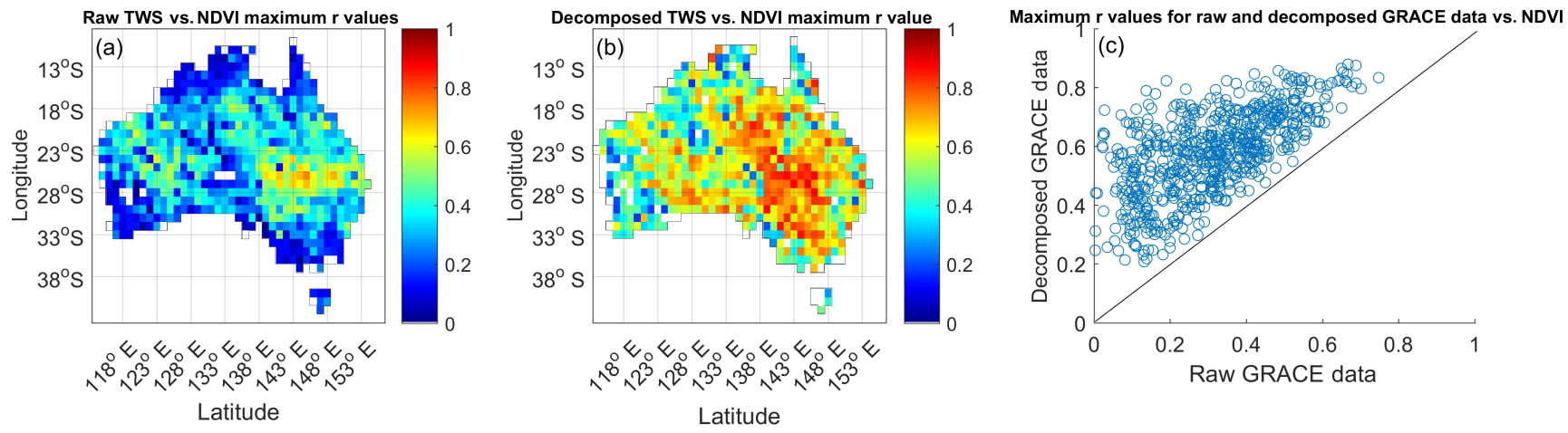

Figure 4. (a) The $r$ values of the relationship between the raw TWS* and NDVI*. (b) The $r$ values of the relationship between the decomposed TWS* and NDVI*. (c) A scatter plot of the $r$ values of both relationships shows a clear improvement in the results when the decomposed data are used.

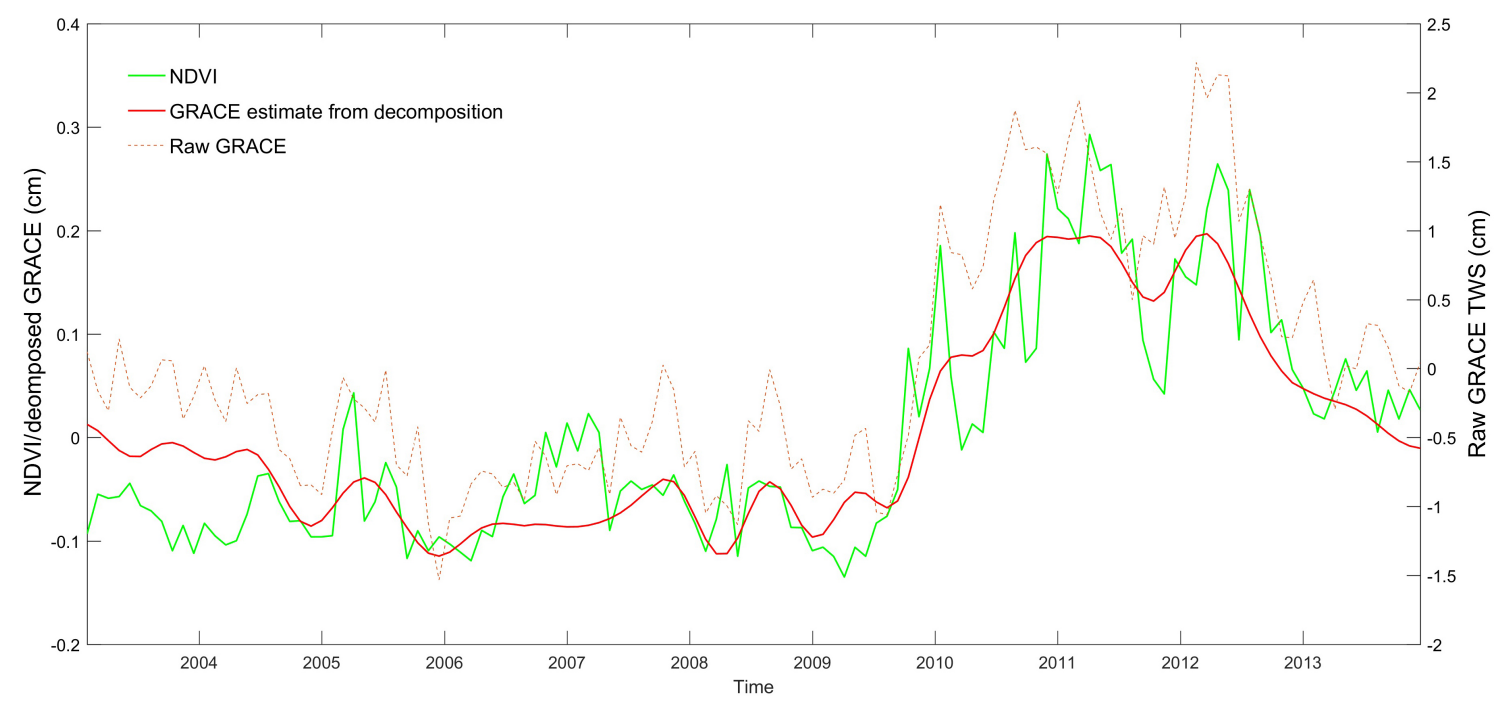

Figure 5. An example of the time series from a single cell. The new estimate uses the coefficients from $A 4_{0}$, $A 4_{6}$, and $D 4$ as selected by the stepwise regression. Pearson's coefficient $(r)$ between the decomposed GRACE estimate and NDVI* is 0.872, compared with 0.665 when using raw GRACE TWS*.

dicator of an ecosystem's capacity to store water, as well as carbon and nitrogen (Schwinning et al., 2004).

The weight distribution of different decompositions across land use types generally matches our physical understanding. Note firstly that all five land use types have $A 4_{\mathrm{L}}$ as a large component of their total weight. This is a further indication of the general response of vegetation to low-frequency changes in water storage. Forested areas are only composed of $A 4_{\mathrm{L}}, D 4_{\mathrm{L}}$, and $D 3_{\mathrm{L}}$ and are ignorant of high-frequency changes in water storage. This matches our physical understanding as forests have deeper root systems, which rely on seasonal changes or long-term hydrological trends. Interestingly, shrublands, grasslands, and savannas show a nearidentical composition of relatively weighted decompositions, with grasslands showing a slightly higher weight percentage of $D 1$ and $D 2$. The three land use types are all grass dom- inated, with the addition of sparse trees and shrubs in savannas and shrublands. As the resolution of GRACE cannot pick up these additions, it is possible that they all appear as grassland, or at least skewed that way, as that is the dominant vegetation cover. The dominance of $D 1$ and $D 2$ across these land use types is typical of relatively dynamic, grassdominated regions.

The combination of weights that make up the total for agricultural land is less straightforward. $D 2$ and $A 4_{\mathrm{L}}$ contribute to large portions of the total. One major difference between agricultural land and the other land use types is the anthropogenic contributions to the land, including the additions of livestock grazing (Yates et al., 2000). The other land use types are generally self-sufficient or limiting at the cell scale, so the interruption of the natural cycle of the vegeta- 

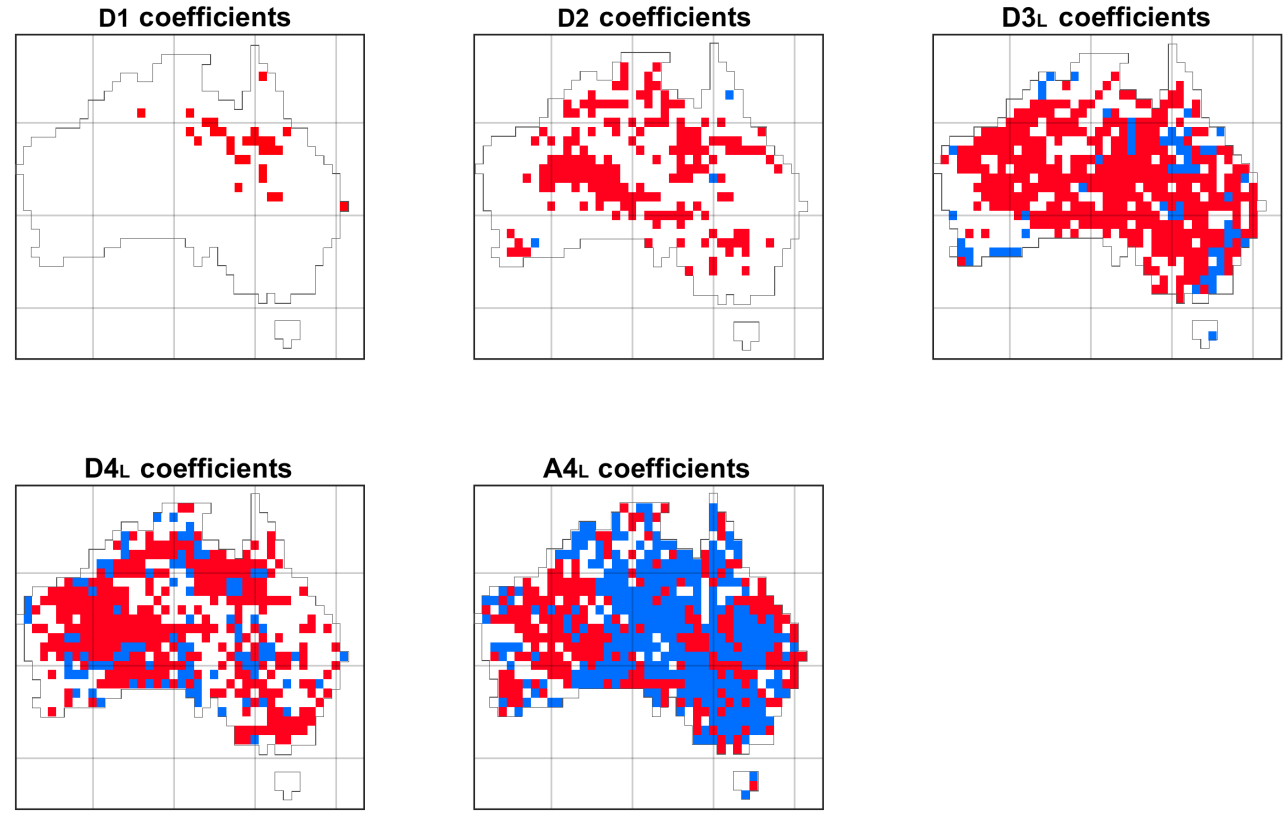

Figure 6. Patterns of the coefficients for each decomposition level. For $D 1$ and $D 2$, no lags are used; for these, red represents a positive coefficient and blue represents a negative coefficient. For $D 3_{\mathrm{L}}, D 4_{\mathrm{L}}$, and $A 4_{\mathrm{L}}$ (which include lags), red represents cells where all coefficients are positive and blue represents cells where at least one lag had a negative coefficient.

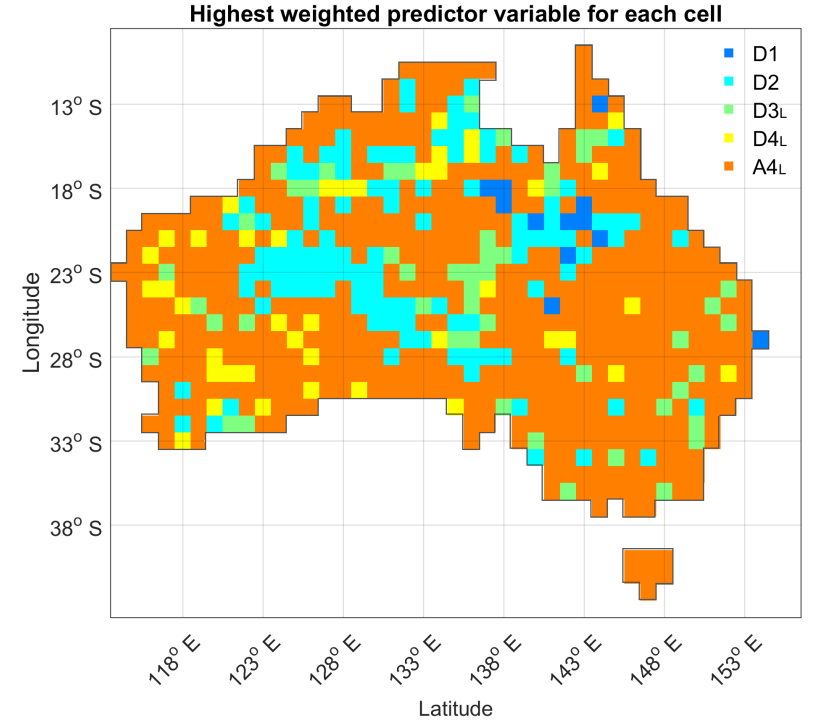

Figure 7. The variable with the highest relative weight in the regression for each cell across Australia. A4 is the most dominant; however $D 2$ is prominent in distinct areas throughout central Australia. $D 1, D 3_{\mathrm{L}}$, and $D 4_{\mathrm{L}}$ all occur but with little spatial coherence.

tion in agricultural areas is a potential anomaly, disturbing any predictable composition of relative weights.

Our method of using decomposed terrestrial water storage as an improved indicator of surface greenness has potential environmental benefits. It allows for an improved un-

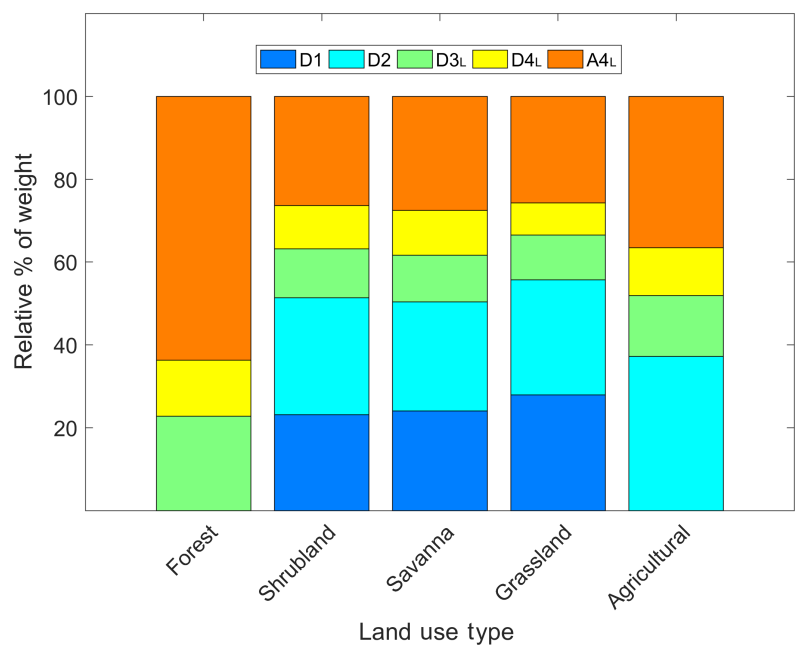

Figure 8. The relative weight of each decomposed TWS* for each land use type. Forests are $A 4_{\mathrm{L}}$ dominated; shrublands, savannas and grasslands are very similar with relative equal weights of $D 1, D 2$, and $A 4_{\mathrm{L}}$ and agricultural land is dominated by $D 2$ and $A 4_{\mathrm{L}}$.

derstanding of how vegetation responds to changes in water storage both spatially and temporally. This in turn serves as a better indicator of ecosystem performance and carbon fluxes. With predictions of terrestrial water storages to decline in the future (Oki and Shinkiro, 2006), our method could be highly useful for predicting carbon fluxes and ecosystem performance at a large scale based on future water-storage es- 
timates. Furthermore, the global mapping of GRACE and NDVI (as well as other vegetation indexes) means that it could be applied globally.

\section{Conclusion}

In this study we aimed to increase the understanding of largescale ecosystem responses to water storage by investigating the links between GRACE TWS* and NDVI* using decomposed TWS* data. Combinations of decomposed GRACE TWS* data show an improved relationship with NDVI* compared to using raw GRACE TWS* data alone. Varying decomposed frequencies shows spatial coherence in parts of the country, sometimes independently and sometimes overlapping other decomposed frequencies. Generally, NDVI is influenced by low-frequency changes in water storage; however, there are some areas which are also sensitive to highfrequency changes. The NDVI is susceptible to a memory effect which depends on previous TWS conditions (generally 6 months). The total influence of NDVI changes is made up of storage changes over different time periods. These vary depending on the land use type and the results are aligned with our physical understanding. This analysis could be further used to continue to improve our understanding of vegetative responses to water storage change in Australia and globally, and to benefit predictions of ecosystem performance and carbon fluxes.
Data availability. Data and codes can be accessed by contacting the corresponding author. 
Appendix A

D10 coefficients

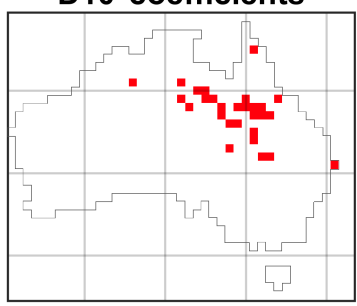

D31 coefficients

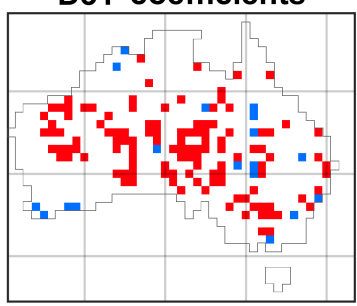

D41 coefficients

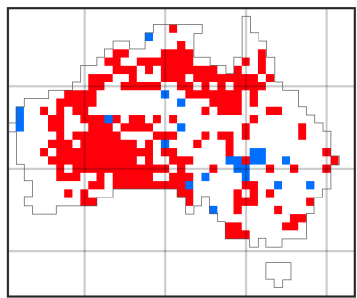

D21 coefficients

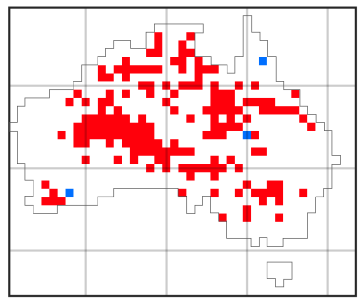

D32 coefficients

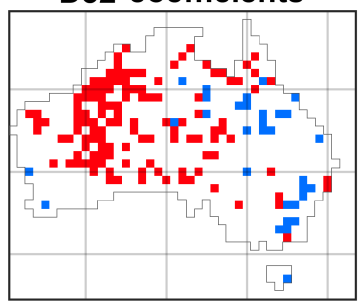

A40 coefficients

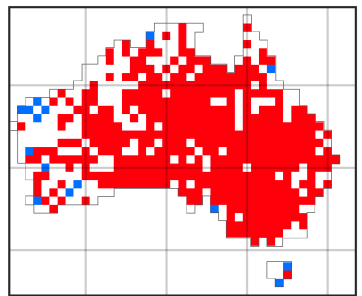

D30 coefficients

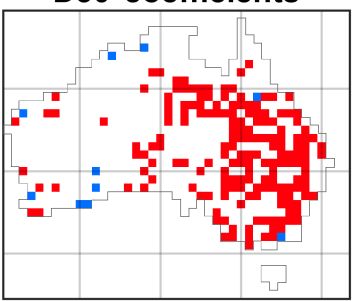

D40 coefficients

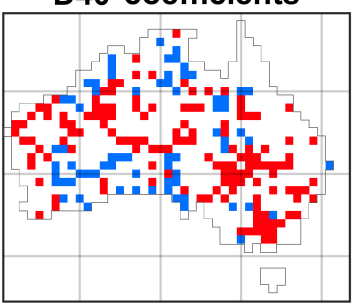

A46 coefficients

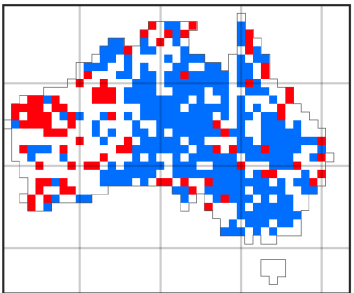

Figure A1. Coefficients for all nine decomposition levels including lags. Red represents a positive coefficient and blue represents a negative coefficient. 
Competing interests. The authors declare that they have no conflict of interest.

Acknowledgements. The authors would like to acknowledge the reviewers and editor of this paper for their helpful suggestions and recommendations which led to its publication.

Edited by: Patricia Saco

Reviewed by: three anonymous referees

\section{References}

Andrew, R. A., Guan, H., and Batelaan, O.: Estimation of GRACE water storage components by temporal decomposition, J. Hydrol., 552, 341-350, 2017.

Backer, T. R., Swaine, M. D., and Burslem, D. F.: Variation in tropical forest growth rates: combined effects of functional group composition and resource availability, Perspect. Plant Ecol., 6, 21-36, 2003.

Bos, M. G., Kselik, R. A., Allen, G. R., and Molden, D. J.: Water Requirements for Irrigation and the Environment, Springer, New York, the Netherlands, 2009.

Campos, P. G., Moran, S., Huete, A., Zhang, Y., Bresloff, C., Huxman, T. E., Eamus, D., Bosch, D. D., Buda, A. R., Gunter, S. A., Scalley, T. H., Kitchen, S. G., McClaran, M. P., McNab, W. H., Montoya, D. S., Morgan, J. A., Peters, D. P. C., Sadler, J. E., Seyfried, M. S., and Starks, P. J.: Ecosystem resilience despite large-scale altered hydroclimatic conditions, Nature, 494, 349352, 2013.

Chen, T., De Jeu, R., Lui, Y., Van der Werf, G. R., and Dolman, A. J.: Using satellite based soilmoisture to quantify the water driven variability, Remote Sens. Environ., 140, 330-338, 2014.

Chen, Y., Yang, K., Qin, J., Zhao, L., Tang, W., and Han, M.: Evaluation of AMSR-E retrievals and GLDAS simulations against observations of a soil moisture network on the central Tibetan Plateau, J. Geophys. Res.-Atmos., 118, 4466-4475, 2013.

Donohue, R. J., McVicar, T. R., and Roderick, M. L.: Climaterelated trends in Australian vegetation cover as inferred from satellite observations, 1981-2006, Glob. Change Biol., 15, 10251039, 2008.

Farrar, T. J., Nicholson, S. E., and Lare, A. R.: The influence of soil type on the relationships between NDVI, rainfall, and soil moisture in semiarid Botswana. II. NDVI response to soil moisture, Remote Sens. Environ., 50, 121-133, 1994.

Friedl, M. A., McIver, D. K., Hodges, J., Zhang, X. Y., Muchoney, D., Strahler, A. H., and Schaaf, C.: Global land cover mapping from MODIS: algorithms and early results, Remote Sens. Environ., 83, 287-302, 2002.

Goupillaud, P., Grossmann, A., and Morlet, J.: Cycle-octave and related transforms in seismic signal analysis, Geoexploration, 23, 85-102, 1984.
He, X. and Guan, H.: Multiresolution analysis of precipitation teleconnections with large-scale climate signals: A case study in South Australia, Water Resour. Res., 49, 6995-7008, 2013.

Huxman, T. E., Smith, M. D., Fay, P. A., Knapp, A. K., Shaw, M. R., Loik, M. E., Smith, S. D., Tissue, D. T., Zak, J. C., Weltzin, J. F., and Pockman, W. T.: Convergence across biomes to a common rain-use efficiency. Nature, 429, 651-654, 2004.

Landerer, F. and Swenson, S.: Accuracy of scaled GRACE terrestrial water storage estimates, Water Resour. Res., 48, W04531, https://doi.org/10.1029/2011WR011453, 2012.

Liping, D., Rundquist, D. C., and Han, L.: Modelling relationships between NDVI and precipitation during vegetative growth cycles, Int. J. Remote Sens., 15, 2121-2136, 1994.

Long, D., Yang, Y., Wada, Y., Hong, Y., Liang, W., Chen, Y., and Chen, L.: Deriving scaling factors using a global hydrological model to restore GRACE signals, Remote Sens. Environ. 168, 177-193, 2015.

Méndez-Barroso, L. A., Vivoni, E. R., Watts, C. J., and Rodríguez, J. C.: Seasonal and interannual relations between precipitation, surface soil moisture and vegetation dynamics in the North American monsoon region, J. Hydrol., 377, 59-70, 2009.

Nalley, D., Adamowski, J., and Khalil, B.: Using discrete wavelet transforms to analyse trends in streamflow and precipitation in Quebec and Ontario (1954-2008), J. Hydrol., 475, 204-228, 2012.

Nemani, R. R., Keeling, C. D., Hashimoto, H., Jolly, W. M., Piper, S. C., Tucker, C. J., and Running, S. W.: Climate-Driven Increases in Global Terrestrial Net Primary Production from 1982 to 1999 , Science, 300, 1560-1563, 2003.

Oki, T. and Shinkiro, K.: Global hydrological cycles and world water resources, Science, 313, 1068-1072, 2006.

Schwinning, S., Sala, O. E., Loik, M. E., and Ehleringer, J. R.: Thresholds, memory and seasonality: understanding pulse dynamics in arid/semi-arid ecosystems, Oecologia, 141, 191-193, 2004.

Shook, K. R. and Pomeroy, J. W.: Memory effects of depressional storage in Northern Prairie hydrology, Hydrol. Process., 25, 3890-3898, 2011.

Swenson, S. and Wahr, J.: Post-processing removal of correlated errors in GRACE data, Geophys. Res. Lett., 33, L08402, https://doi.org/10.1029/2005GL025285, 2006.

Wang, X. W., Xie, H. J., Guan, H. D., and Zhou, X. B.: Different responses of MODIS-derived NDVI to root-zone soil moisture in semi-arid and humid regions, J. Hydrol., 340, 12-24, 2007.

Yang, Y., Long, D., Guan, H., Scanlon, B. R., Simmons, C. T., Jaing, L., and Xu, X.: GRACE satellite observed hydrological controls on interannual and seasonal variability in surface greenness over mainland Australia, J. Geophys. Res.-Biogeo., 119, 2245-2260, 2014.

Yates, C. J., Norton, C. J., and Hobbs, R. J.: Grazing effects on plant cover, soil and microclimate, Australian Ecology, 25, 3647,2000 . 